\title{
Neurons of the Olfactory Epithelium in Adult Rats Contain Vimentin
}

\author{
James E. Schwob, Nuri B. Farber, and David I. Gottlieb \\ Department of Anatomy and Neurobiology, Washington University School of Medicine, St. Louis, Missouri 63110
}

In the developing nervous system, the intermediate filament protein vimentin is found in the proliferating neuroepithelium and neural crest. As development proceeds, postmitotic neurons cease vimentin expression and neurofilament proteins begin to accumulate. We have shown that olfactory receptor neurons deviate from the general pattern of neuronal intermediate filament expression, in that they continue to express vimentin or a highly vimentin-like protein rather than neurofilament proteins in the adult rat.

With light-microscopic immunohistochemistry, three independently derived antibodies to vimentin label all portions of the primary olfactory projection, including the sensory neuron cell bodies in the olfactory epithelium, the fascicles of the olfactory nerve, and their axonal arbors in the glomeruli of the olfactory bulb. In contrast, anti-neurofilament antisera stain only rare scattered receptor cells and a small number of axons in the olfactory nerve. Electron-microscopic immunohistochemistry shows dense staining of olfactory axons with anti-vimentin.

The vimentin-like immunoreactive material in the olfactory nerve layer was characterized by SDS-PAGE and by immunoblotting. On immunoblots of homogenates of the olfactory nerve, the anti-vimentin monoclonal antibody SBV-21 (Blose et al., 1984) stains only a single protein of $M_{r}=55 \mathrm{kDa}$. This band comigrates with vimentin in crude cytoskeletal material from the neonatal rat brain prepared according to the method of Dahl et al. (1981). SBV-21 does not stain neurofilament triplet proteins or glial fibrillary acidic protein, which are also present in these blots.

These results demonstrate that the vast majority of olfactory receptor neurons and their axons contain vimentin or a protein of similar immunological character and electrophoretic mobility, while identifiable expression of neurofilament proteins is confined to a very small subpopulation. Hence, the switch in intermediate filament proteins that normally accompanies neuronal maturation is arrested in most olfactory neurons, and a "juvenile" biochemical marker is retained. This population of neurons is also unique among mammalian neurons in several other respects, including that olfactory neurons die during normal adult life or following injury and then are replaced from a proliferating pool of stem cells.

Intermediate filaments are morphologically similar, $8-11 \mathrm{~nm}$ components of the cytoskeleton found in many different cell types. However, there are five immunologically and biochem-

\footnotetext{
Received June 10, 1985; revised July 29, 1985; accepted July 31, 1985.

We would like to thank Jeanette Mosher for her excellent technical help with the EM immunohistochemical part of this work. We would especially like to thank Dr. Stephen Blose for advice and encouragement at the early stages of this project and for the generous supply of the anti-vimentin monoclonal antibody SBV-21. We would also like to acknowledge the thoughtful comments and criticisms of Drs. Mark B. Willard and Joshua R. Sanes during the course of this project and on this manuscript. This work was supported by NIH Grant NS 12867 , and J.E.S. was supported by postdoctoral NIH Training Grant NS 07076.

Correspondence should be addressed to James E. Schwob, M.D., Ph.D., at the above address.

Copyright (C) 1986 Society for Neuroscience $0270-6474 / 86 / 010208-10 \$ 02.00 / 0$
}

ically distinct classes of subunit proteins, which are limited to specific cell types and tissues; these include the proteins of the neurofilament triplet which are found in PNS and CNS neurons, glial fibrillary acidic protein (GFAP), which is found in astrocytes in the CNS, and vimentin, which was originally described in cells of mesenchymal lineage (reviewed by Lazarides, 1980; Osborn et al., 1981). During the development of the nervous system a characteristic change in intermediatc filament protein composition occurs in both neurons and glia. Many, and possibly all, cells of the proliferating neuroepithelium of the CNS (including both neuronal and glial precursors) and of the migrating neural crest contain abundant vimentin (Cochard and Paulin, 1984; Houle and Federoff, 1983; Tapscott et al., 1981a, b; Ziller et al., 1983). Subsequently, neuroblasts withdraw from the proliferative cell cycle, vimentin expression ceases, and neurofilament proteins accumulate in the vast majority of PNS and CNS neurons. For a brief period of time during embryonic dcvclopment, vimentin and neurofilament proteins coexist in some young neurons or neuronal precursors both in vivo and in vitro before vimentin disappears completely (Bennett and DiLullo, 1985a, b; Bennett et al., 1982; Bignami et al., 1982; Cochard and Paulin, 1984; Jacobs et al., 1982; Tapscott et al., 1981a, b; Ziller et al., 1983).

We report here that the receptor neurons of the olfactory epithelium deviate from the general pattern seen elsewhere in the nervous system. The olfactory sensory cells of the adult express high levels of vimentin or a vimentin-like protein, and neurofilament proteins are found in only a very small subset of these neurons. This observation is of interest because olfactory neurons are exceptional in another regard: They are the only neurons in adult mammals that are replaced following cell death. A continuous proliferation of precursor cells in the olfactory epithelium replaces the receptor neurons lost through natural turnover or experimentally induced injury (Graziadei and Monti Graziadei, 1978; Moulton, 1974). Thus, the olfactory epithelium retains an important juvenile biological function, and its neurons retain a protein characteristic of neuronal precursors and young neurons.

\section{Materials and Methods}

\section{Animals}

Six- to eight-week-old Sprague-Dawley rats were obtained from a barrier isolated facility (Sasco Inc.); these were free of chronic rhinitis or epithelial atrophy as assessed by light-microscopic examination. Litters of newborn rats were used within $24 \mathrm{hr}$ of birth

\section{Materials}

All biochemical and immunohistochemical reagents were reagent grade and obtained from Sigma Chemical Co. unless otherwise specified.

\section{Immunological reagents}

Ascites fluid containing the anti-vimentin mouse monoclonal antibody SBV-21 was the kind gift of Dr. Stephen Blose. This antibody is a mouse $\mathrm{IgG}_{1}$ generated by immunization with electrophoretically purified bo- 
vine lense vimentin (Blose et al., 1984; S. H. Blose, personal communication). By radioimmunoassay (RIA), SBV-21 reacts specifically with vimentin and does not cross-react with other bovine intermediate filaments or tropomyosin. An additional anti-vimentin mouse monoclonal antibody was obtained from Lab Systems, Inc. This antibody was generated against porcine vimentin and bears the designation PKV1 (Lehtonen et al., 1983). It reacts only with vimentin in cytoskeletal preparations from a variety of tissues, including some which also contain desmin (Lehtonen et al., 1983; Virtanen et al., unpublished observations). A polyclonal rabbit anti-vimentin antiserum was the gift of Dr. Richard Hynes. It was raised against electrophoretically purified vimentin from the hamster cell line NIL-8 and stains only vimentin in SDS-PAGE gels of whole cell lysates (Hynes and Destree, 1978). Three goat antisera to neurofilament subunit proteins were the gifts of Drs. Marcie Glicksman and Mark Willard (Hirokawa et al., 1984; Willard and Simon, 1981). The first, designated anti-M/H, was raised against the purified $195 \mathrm{kDa}$ neurofilament subunit protein from rabbits affinitypurified with the $145 \mathrm{kDa}$ subunit and absorbed with the $73 \mathrm{kDa}$ subunit. The second, designated anti-M, was raised against and affinitypurified with the $145 \mathrm{kDa}$ subunit protein as well as cross-absorbed with the $\mathrm{H}$ and $\mathrm{L}$ proteins. The third, designated anti-L, was raised against and affinity-purified with the $73 \mathrm{kDa}$ subunit protein and absorbed with $\mathrm{H}$ and $\mathrm{M}$. Rabbit antiserum to human glial fibrillary acidic protein (anti-GFAP) was the gift of Dr. Larry Eng (Bignami et al., 1972). Rabbit antiserum to chicken muscle desmin was the gift of Dr. Maureen $\mathrm{G}$. Price. This antiserum has been screened against the cytoskeletal proteins of bovine myocardium; on immunoblots, it is specific for desmin (M. G. Price, manuscript in preparation).

Tissue-bound primary antibody was visualized with a biotinylated secondary antibody and an avidin-biotinylated HRP complex (mouse IgG, goat IgG, and rabbit IgG Vectastain ABC kits, Vector Laboratories). The biotinylated horse anti-mouse IgG secondary antibody cross-reacted significantly with peripheral rat tissues, necessitating the preabsorption of this reagent (diluted in phosphate buffered saline containing $20 \%$ normal horse serum) by incubation for $1 \mathrm{hr}$ with a mixture of minced rat tissues, including liver, skeletal muscle, thymus, kidney, lacrimal gland, and salivary gland; this markedly lowered background staining. For the biotinylated rabbit anti-goat IgG and the biotinylated goat anti-rabbit IgG secondary antibodies, the addition of $2 \%$ nonimmune rat serum reduced the background due to nonspecific binding of the secondary antibody to an acceptable level.

\section{Indirect light-microscopic immunohistochemistry}

Various fixation conditions were evaluated for the optimal preservation of antigenicity in cryostat sections, including fresh-frozen unfixed tissue, fresh tissue fixed in acetone after sectioning, and perfusion fixation of tissue with low concentrations of buffered paraformaldehyde and glutaraldehyde. Qualitatively similar results were obtained using each method, but the most consistent retention of immunoreactivity together with good tissue preservation was obtained with a fixative composed of $0.01 \mathrm{M}$ sodium periodate, $0.075 \mathrm{M}$ lysine, and $0.5-1.0 \%$ paraformaldehyde in $0.1 \mathrm{M}$ sodium phosphate buffer at $\mathrm{pH} 7.4$ and $10^{\circ} \mathrm{C}$ (McLean and Nakane, 1974). Adult rats were injected with a lethal dose of sodium pentobarbital, the thoracic cavity was opened, and the aorta was clamped. The blood was rinsed out with $50 \mathrm{ml}$ of PBS before $400 \mathrm{ml}$ of fixative was delivered under a constant pressure of $100 \mathrm{~mm}$ of $\mathrm{Hg}$. The olfactory bulbs and anterior forebrain were removed either alone or in continuity with the posterior nasal septum and turbinates and their epithelial lining. In the latter case, the tissue was decalcified by immersion in a saturated solution of EDTA at pH 7.4 for $48 \mathrm{hr}$ at $4^{\circ} \mathrm{C}$. The fixed tissue was then equilibrated in $30 \%$ sucrose in PBS, embedded in OCT, frozen in liquid nitrogen, and stored at $-70^{\circ} \mathrm{C}$ before sectioning. Cryostat sections 6$12 \mu \mathrm{m}$ thick were collected on glass slides that had been coated with a gelatin-chrome alum solution and were stored at $-20^{\circ} \mathrm{C}$ without apparent deterioration in antigenicity for several months.

Immediately prior to the application of the primary antibody, the sections were warmed to room temperature and rapidly dehydrated through to $100 \%$ cold alcohol or acetone extracted before rehydrating; this treatment improved antibody penetration and reduced nonspecific background. Nonspecific binding of the primary antibody to the sections was blocked by soaking the sections in PBS-5\% normal horse serum (LM rinse buffer) for at least $10 \mathrm{~min}$. Incubation with the primary antibodies was for $1 \mathrm{hr}$ at room temperature in a solution of $0.5 \%$ Triton X-100-PBS-20\% normal serum (from the same species as the corresponding secondary antibody). Primary antibodies were used at the following dilutions: anti-vimentin monoclonal antibody SBV-2l at $1: 1000$, anti-vimentin monoclonal antibody PK-V1 at $1: 20$, anti-vimentin polyclonal antiserum at 1:250, anti-neurofilament antisera at 2 $\mu \mathrm{g} / \mathrm{ml}$, anti-GFAP antiserum at $1: 400$, and anti-desmin antiserum at 1:80. For each of these, incubation of the tissue with nonimmune serum at equivalent concentrations was done as a control. After this incubation, the tissue was washed in three changes of cold LM rinse buffer for 10 min each.

The biotinylated secondary antibodics werc diluted in PBS-20\% normal serum (from the same species as the secondary antibody) and put on the sections for $1 \mathrm{hr}$ at room temperature. The biotinylated horse anti-mouse was used at a final dilution of 1:50, while both the biotinylated rabbit anti-goat and the biotinylated goat anti-rabbit were used at 1:150. At the end of this incubation, the tissue was washed in three changes of cold LM rinse buffer for $5 \mathrm{~min}$ each. The avidin-biotinylated HRP complex was used as recommended by the manufacturer, and the tisue was incubated in it for $1 \mathrm{hr}$, followed by three changes of rinse buffer for 5 min each.

The distribution of the HRP-labeled complex was visualized using $0.2 \%$ diaminobenzidine (DAB) and $0.01 \%$ hydrogen peroxide in $0.1 \mathrm{~m}$ sodium citrate buffer at $\mathrm{pH}$ 5.1. The reaction was allowed to proceed for $15 \mathrm{~min}$, and then the sections were rinsed in three changes of water for a total of $15 \mathrm{~min}$ before cither dircetly dehydrating and mounting them in DPX mountant (Gallard-Schlesinger Inc.) or first counterstaining them lightly in Harris' hematoxylin.

\section{Indirect electron-microscopic immunohistochemistry}

For the EM demonstration of the distribution of vimentin-like immunoreactivity, the protocol differed from that used at the light-microscopic level as follows. With regard to fixation, the best balance of preservation of antigenicity and tissue ultrastructure was achieved when the animal was perfused with $200 \mathrm{ml}$ of $2 \%$ paraformaldehyde in 0.1 $\mathrm{M}$ sodium acetate buffer at $\mathrm{pH} 6.5$ followed by $200 \mathrm{ml}$ of $2 \%$ paraformaldehyde $/ 0.25 \%$ glutaraldehyde in $0.05 \mathrm{~m}$ sodium borate buffer at $\mathrm{pH}$ 10.5 (Berod et al., 1981). The olfactory bulbs were removed and immersed in the latter fixative for another hour, rinsed in PBS- $4 \%$ sucrose (EM rinse buffer), and embedded in 3\% agar. Vibratome sections 250 $\mu \mathrm{m}$ thick were cut from the block and washed in EM rinse buffer for 1 $\mathrm{hr}$. Further tissue preparation up to incubation in the primary antibody followed the protocol of Eldred and co-workers (1983). The tissue sections were transferred into $1 \%$ sodium borohydride in EM rinse buffer for $30 \mathrm{~min}$ and then washed in three changes of EM rinse buffer for a total of $1 \mathrm{hr}$ before dehydration and rehydration through $40 \%$ alcohol in PBS at room temperature. Nonspecific binding of antibody to the tissue was blocked with EM rinse buffer with $5 \%$ normal horse serum for $1 \mathrm{hr}$ followed by overnight incubation at $4^{\circ} \mathrm{C}$ with either the monoclonal antibody SBV-21 or nonimmune mouse serum at 1:500 dilutions in $0.1-0.2 \%$ Triton X-100 in PBS containing $20 \%$ normal horse serum. After washing in three changes of rinse buffer with $5 \%$ normal horse serum for a total of $1 \mathrm{hr}$, the sections were incubated for $7 \mathrm{hr}$ with the same concentration of preabsorbed biotinylated horse anti-mouse IgG as was described above, washed again, and transferred into the avidinbiotinylated HRP solution for overnight incubation at $4^{\circ} \mathrm{C}$. After a final wash in rinse-buffer with $5 \%$ normal horse serum, the sections were reacted with the DAB solution for 5 min, rinsed, postfixed in $1 \%$ glutaraldehyde in $0.1 \mathrm{~m}$ phosphate buffer for $1 \mathrm{hr}$, and rinsed again. They were osmicated for $2 \mathrm{hr}$ in a solution of $1 \%$ osmium tetroxide in rinse buffer, dehydrated through propylene oxide, and embedded in EponAraldite. Ultrathin sections taken near the surface of the block were examined with a Zeiss ZM-10 EM.

\section{Biochemical characterization of immunoreactive material}

\section{Olfaclory nerve and neonatal forebrain preparations}

Biochemical identification of the immunoreactive material was done by SDS-PAGE and immunostaining after electrophoretic transfer of proteins to nitrocellulose paper (Western blotting; Towbin et al., 1979). Two types of preparations were used: a crude homogenate of the olfactory nerve layer (to provide the most complete representation of the protein composition of the olfactory nerve) and a cytoskeletal preparation from neonatal rat forebrain that is highly enriched for vimentin (after Dahl et al., 1981).

To prepare the olfactory nerve layer homogenate, the outer rind of the olfactory bulb (which was largely composed of the olfactory nerve 
layer) was dissected free on ice and stored at $-70^{\circ} \mathrm{C}$. Thirty milligram of tissue was homogenized in $3 \mathrm{ml}$ of denaturing solution [1 $\mathrm{mm}$ Tris buffer at pH 8.0, 0.5 mm EDTA at pH 8.0, 1.5\% SDS, 2 mм DTT, $0.001 \mathrm{~mm}$ benzamidine, and $0.5 \mathrm{~mm}$ phenylmethylsulfonyl chloride (PMSF)] with a motorized Potter-Elvehjem tissue grinder. The homogenate was boiled for $5 \mathrm{~min}$ and then centrifuged at $140,000 \times g$ for 45 min at room temperature. The supernatant was made $10 \%$ in glycerol and $0.001 \%$ in Bromphenol blue and used for SDS-PAGE.

Cytoskeletal proteins highly enriched in vimentin were prepared by slight modification of the method of Dahl et al. (1981). One gram of neonatal rat forebrain, excluding the olfactory bulbs, was homogenized in $20 \mathrm{ml}$ of Triton extraction buffer (TEB) at $0^{\circ} \mathrm{C}(1 \%$ Triton X-100, $0.6 \mathrm{M} \mathrm{KCl}, 2 \mathrm{~mm}$ EDTA, $1 \mathrm{~mm}$ EGTA, $0.067 \mathrm{mg} / \mathrm{ml}$ pepstatin A, 0.133 $\mathrm{mg} / \mathrm{ml}$ leupeptin, $0.5 \mathrm{mg} / \mathrm{ml}$ p-tosyl-L-arginine methyl ester ( $p$-TAME), $0.001 \mathrm{M}$ benzamidine, and $0.5 \mathrm{~mm}$ PMSF in PBS) at $4^{\circ} \mathrm{C}$ with a motor driven Potter-Elvehjem tissue grinder. This homogenate was passed through a 27 gauge needle to shear DNA and then centrifuged at $12,000 \times g$ for $10 \mathrm{~min}$. The pellet was rehomogenized in TEB at $20^{\circ} \mathrm{C}$ and then recentrifuged at $12,000 \times g$ for an additional $10 \mathrm{~min}$. The pellet, which contains the cytoskeletal elements, was solubilized by boiling for $10 \mathrm{~min}$ in denaturing solution- $10 \%$ glycerol $-0.001 \%$ Bromphenol blue and then clarified by centrifugation at $48,000 \times \mathrm{g}$ for 30 min. The supernatant was used for SDS-PAGE.

\section{SDS-PAGE}

Protein concentrations of the supernatants were determined by the method of Bramhall et al. (1969). Samples of the preparations were run on $7-12 \%$ polyacrylamide gradient gels following the method of Laemmli (1971).

\section{Electrophoretic transfers and immunoblots}

After separation by SDS-PAGE, a portion of the gel was stained with Coomassie blue, and the proteins in the remaining portion were electrophoretically transferred to nitrocellulose paper (Schleicher and Schuell, $0.45 \mu \mathrm{m}$ pore size) for $400 \mathrm{~V}$-hr using a Biorad Trans Blot Cell according to the method of Towbin et al. (1979). After transfer, the paper was rinsed in PBS, and nonspecific immunoreactivity to proteins on the strips was blocked by incubation for $30 \mathrm{~min}$ in PBS with $5 \%$ normal serum (from the species in which the corresponding secondary antibody was raised). The primary antibodies were diluted in PBS with $20 \%$ normal serum as follows: SBV-21 at 1:1000, nonimmune mouse serum at 1:1000, anti-GFAP at 1:1000, nonimmune rabbit serum at 1:1000, anti-neurofilament antisera at $0.2 \mu \mathrm{g} / \mathrm{ml}$, and nonimmune goat serum at $2 \mu \mathrm{g} / \mathrm{ml}$. The nitrocellulose strips were incubated for $2 \mathrm{hr}$ in the primary antibody, washed in three changes of PBS with 5\% normal serum for a total of $30 \mathrm{~min}$, incubated for $1.5 \mathrm{hr}$ with biotinylated secondary antibodies at a dilution of 1:200 in PBS-20\% normal serum, washed again, and incubated for $1.5 \mathrm{hr}$ with avidin-biotinylated HRP as recommended by the manufacturer. The complex was visualized by reaction in the DAB solution for $45 \mathrm{sec}$, rinsed in water, and allowed to air-dry.

\section{Results}

LM and EM immunohistochemistry were used to demonstrate the expression of vimentin-like immunoreactivity in the olfactory receptor neurons of the adult rat. Using SDS-PAGE and Western blots, we have characterized the antigen as vimentin or a protein of identical mobility as vimentin.

Figure 1. Cryostat section of a portion of the posterior nasal cavity stained with the anti-vimentin monoclonal antibody SBV-21. A, This photomicrograph includes the nasal septum (to the left) and parts of two lateral turbinates, which are lined by olfactory mucosa. Note the staining of cells in the olfactory epithelium (oe); in the submucosa there is staining of the fascicles of the olfactory nerve (on), which stands out from the staining of blood vessels and connective tissue. $B$, Photomicrograph of area designated by the box in $A$. In the epithelium, the cytoplasmic staining is largely perinuclear, but some slender labeled processes extend toward the apical surface of the epithelium (arrowhead) and toward the basal lamina $(b l)$, which indicates that the labeled cells are bipolar in shape. In the submucosa, the fascicles of the olfactory nerve (on) are densely stained. $C$, Photomicrograph of olfactory epi-
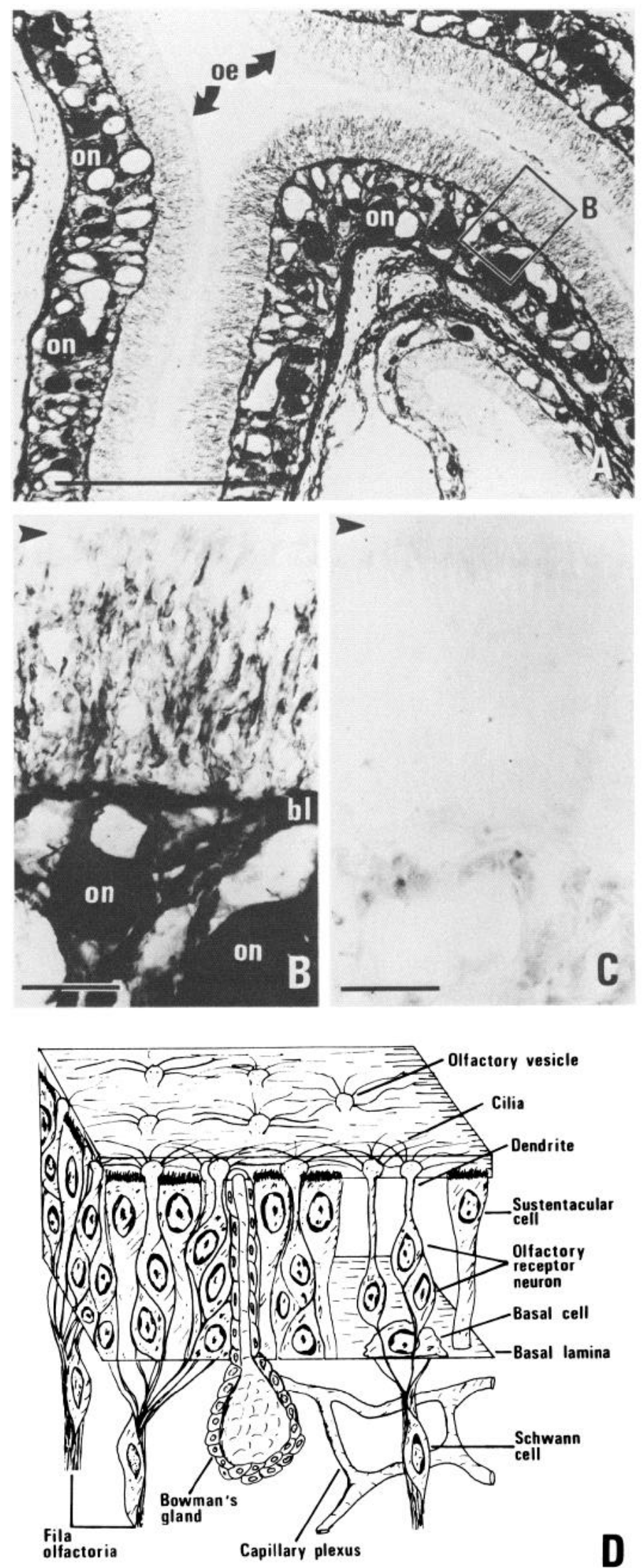

thelium from an adjacent cryostat section incubated with nonimmune mouse serum for negative control. Scale bars, $100 \mu \mathrm{m}$ for $A ; 10 \mu \mathrm{m}$ for $B$ and $C$. D. Schematic drawing of the histology of the olfactory mucosa after Monrath et al. (1983). Fascicles of the olfactory nerve are designated "fila olfactoria." 


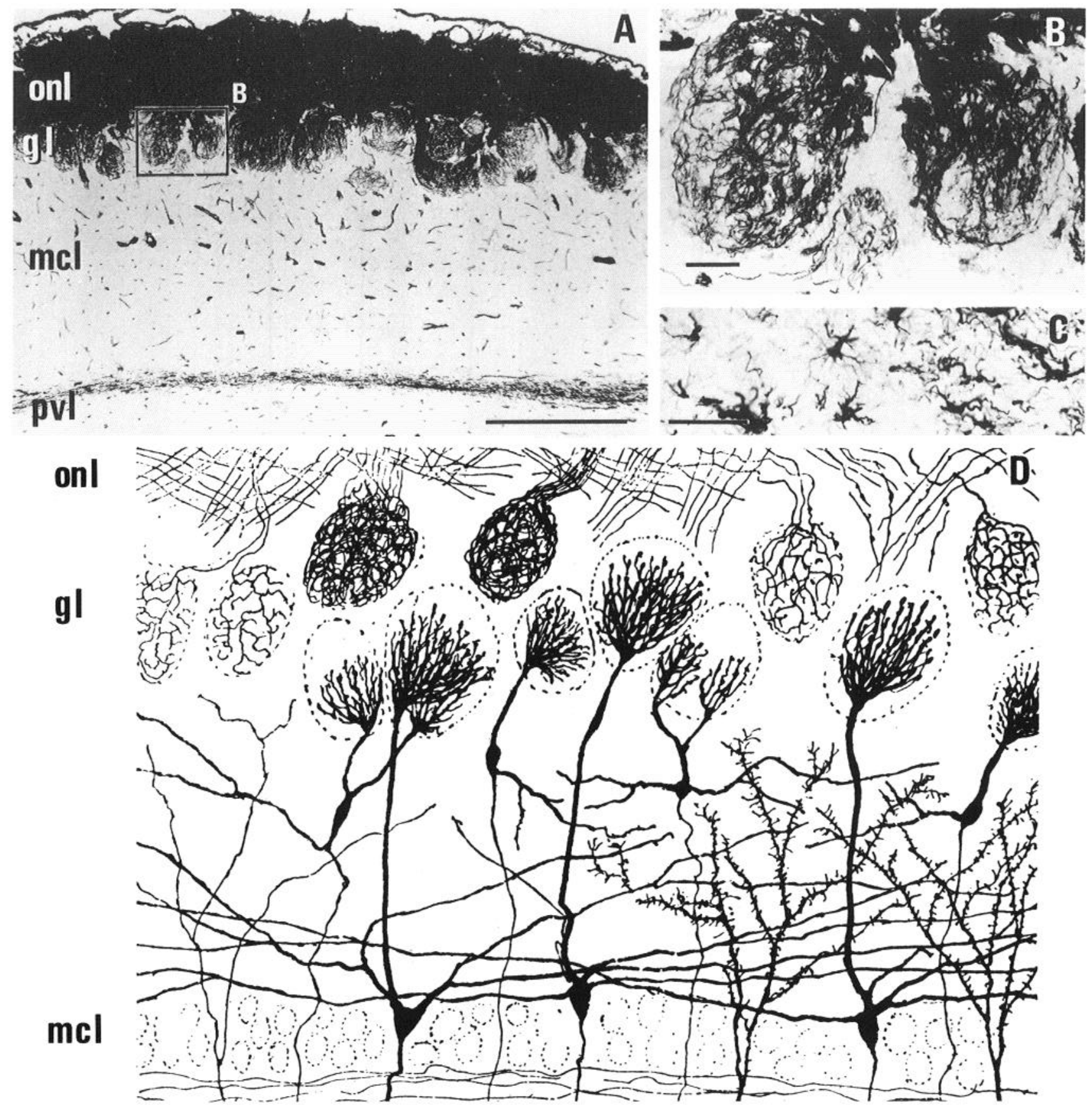

Figure 2. A, Photomicrograph of a coronal cryostat section of the adult rat olfactory bulb stained following incubation with anti-vimentin monoclonal antibody SBV-21. At the external surface of the bulb, note the dense staining of the olfactory nerve layer (onl), which extends into the subadjacent glomeruli $(g l)$. There is also staining of the meninges, blood vessels throughout the bulb, and glial cells in the white matter of the periventricular layer $(p v l)$. The position of the mitral cell layer $(\mathrm{mcl})$ is indicated for comparison with $D$. $B$, Photomicrograph of the glomeruli designated by the box in $A$. Note the resemblance of the stained fibers that fill the glomeruli with the arborizations of the olfactory axons illustrated in $D$. C, High-power photomicrograph of stained glial cells in the periventricular layer. $D$, Drawing after Cajal (1911) of the neuronal elements of the Golgi-stained olfactory bulb. In the glomerular layer, the axonal arbors of the olfactory nerves contact the mitral and tufted cells of the olfactory bulb. Scale bars, $100 \mu \mathrm{m}$ in $A ; 10 \mu \mathrm{m}$ in $B$ and $C$.

\section{Localization of vimentin-like immunoreactivity in the olfactory projection}

The two monoclonal anti-vimentin antibodies SBV-21 and PK$\mathrm{V} 1$ and the polyclonal anti-vimentin antiserum label all portions of the primary olfactory projection, including the sensory neuron cell bodies in the olfactory epithelium, their axons in the fascicles of the olfactory nerve, and their terminal portions in the glomeruli of the olfactory bulb (Figs. 1 and 2). Following indirect immunohistochemical staining of the olfactory epithelium, the
HRP reaction product is deposited in the perinuclear cytoplasm of receptor neurons in the middle layers of the epithelium; this localization to the perinuclear cytoplasm is confirmed in sections counterstained with hematoxylin (not illustrated). On close examination with the light microscope, labeled dendritic processes from the neurons can be identified and seen to ascend to the apical epithelial surface, and labeled axons of the receptor cells descend to the basal lamina (Fig. 1, $A, B$ ). Nonimmune mouse serum does not stain these elements (Fig. 1C). The un- 

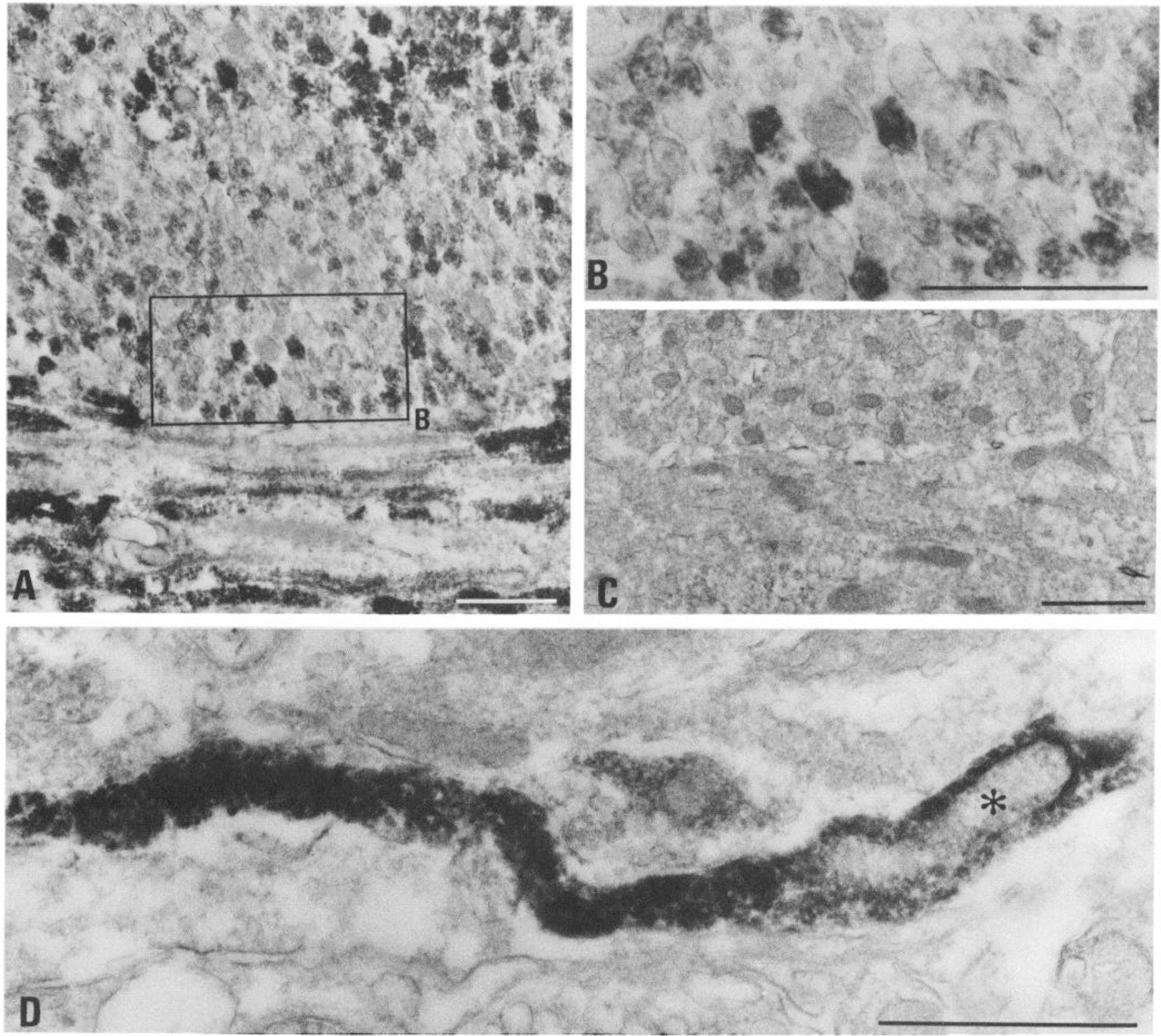

Figure 3. Electron micrographs of the olfactory nerve layer, which was immunohistochemically stained prior to plastic embedding. $A$, SBV-21 staining in the superficial part of the olfactory nerve layer. In the fascicle of axons cut in cross section and in the other cut longitudinally, a majority of the axons contain electron-dense, globular DAB reaction product in their cytoplasm. $B$, Higher power of boxed area in $A$ showing multiple crosssectioned axons with varying amounts of HRP reaction product. $C$, Olfactory nerve layer from tissue incubated with normal mouse serum as a negative control. No staining is seen; the darker profiles in the axon are mitochondria. $D$, SBV-21 staining near the border of the olfactory nerve and glomerular layers; in the axon, dense reaction product is deposited throughout the cytoplasm but is excluded from the mitochondrion (asterisk). Scale bars, $1 \mu \mathrm{m}$ throughout.

derlying submucosa contains densely labeled fascicles of the olfactory nerve that are clearly distinct from stained blood vessels and connective tissue; packed bundles of labeled olfactory axons would be expected to produce a solid staining of the fascicles such as this. The labeled fascicles run caudally and dorsally, penetrate the cribriform plate, and coalesce into the olfactory nerve layer around the outside of the olfactory bulb. Close examination of this layer shows that the dense staining of the olfactory nerve layer actually consists of interweaving bundles of fibers (Fig. 2A). At their terminus, stained axons descend from the olfactory nerve layer into the subjacent glomeruli, where they form a dense plexus of labeled fibers (Fig. $2 B$ ). Elsewhere in the olfactory bulb, the anti-vimentin mono- clonal antibodies and polyclonal antiserum stained the leptomeninges, blood vessels, and some glia in the white matter of the periventricular layer (Fig. $2 C$ ). Staining with these antibodies in other portions of the brain and in several peripheral tissues is entirely consistent with that described for anti-vimentin antisera and other monoclonal antibodies, including the prominent staining of radial glial elements and the neuroepithelium in the CNS early in the development (Osborn et al., 1984; Schnitzer et al., 1981; Shaw et al., 1981; Yen and Fields, 1981).

Supporting cells as well as receptor neurons or their processes are found throughout the olfactory projection. Therefore, it is important to establish at all levels of the primary olfactory projection that these monoclonal antibodies actually stain receptor 
neurons and their axons. Several lines of evidence can be adduced at the light-microscopic level to support the assignment of the major component of this vimentin-like immunoreactivity to the olfactory neurons per se, rather than the supporting cell elements.

The stained cells in the olfactory epithelium may be identified as neurons and distinguished from supporting cells by several criteria, including their position in the middle of the epithelium where neuronal somata are found. In contrast to the sensory neurons, the nuclei of the sustentacular cells are located more superficially in the epithelium (Graziadei and Monti Graziadei, 1979), and there is none of the perinuclear type of cytoplasmic staining in this layer of the epithelium. In addition, the antivimentin-stained cells of the olfactory epithelium have a bipolar shape with labeled apical and basal processes, and this appearance closely resembles the morphology of receptor cells as shown by Golgi staining (Cajal, 1911), by staining with antiserum to olfactory marker protein, which is specific to the primary olfactory projection (Monti Graziadei et al., 1977) and by electron microscopy (Graziadei and Monti Graziadei, 1979). In the olfactory nerve layer, the uniform and intense anti-vimentin staining is consistent with the high density of olfactory axons seen with the EM (Andres, 1965; Barber and Lindsay, 1982; Doucette, 1984; Pinching and Powell, 1971). In contrast, supporting cell processes are far less abundant and form septa that separate bundles of olfactory axons. These cells and their processes stain with anti-GFAP antisera, forming a pattern that is clearly distinguishable from that seen with anti-vimentin (Barber and Lindsay, 1982; cf. Figs. 2 and 6). Finally, the anti-vimentin stained fibers that descend from the olfactory nerve layer and arborize in the glomeruli very closely resemble olfactory axons as visualized by Golgi staining (Cajal, 1911; Valverde, 1965) and in low-power electron micrographs (Pinching and Powell, 1971; cf. Fig. 2, B, D).

These findings provide strong but indirect support for the proposition that vimentin or a highly vimentin-like material is expressed by the receptor neurons and the axons of the primary olfactory projection in adult rats. In order to eliminate the formal possibility that the axon-like pattern of anti-vimentin staining is due to some other closely associated but nonaxonal element, EM immunohistochemistry was done with SBV-21.

EM examination demonstrates that SBV-21 does label olfactory axons in the olfactory nerve layer and that this type of staining is largely responsible for the light-microscopic results. These labeled axons have diameters on the order of $0.2 \mu \mathrm{m}$. Superficially in the olfactory nerve layer, they are arranged in closely packed bundles of many axons (Fig. 3, A, C); more deeply, the stained axons follow a slightly more torturous course as they enter the glomerular neuropil (Fig. 3D). By their individual appearance and their compaction into bundles, the stained axons are identical to descriptions of olfactory axons in routine electron-microscopic material (Andres, 1965; Pinching and Powell, 1971). Heterogeneity in axonal staining is apparent from examination of the illustrated electron micrographs. While most of the axons are stained (to varying extents), not all contain reaction product. Limited antibody penetration may account for this lack of uniform staining, since the fields illustrated by these micrographs were on the order of 10-20 $\mu \mathrm{m}$ from the surfaces of the block. Indeed, near the external surfaces of the block, a vast majority of the axons are stained, and this correlates well with the density of staining seen with the light microscope; the percentage of labeled profiles falls with distance from the block surfaces. There is no staining following incubation with the nonimmune mouse serum at any location relative to the block surfaces (Fig. 3, $A$ vs $C$ ). In addition to the olfactory axons, endothelial cells and some of the glial cells of the olfactory nerve layer are labeled. However, this glial cell component is much sparser and contributes much less to the overall pattern of the staining than does the axonal labeling.

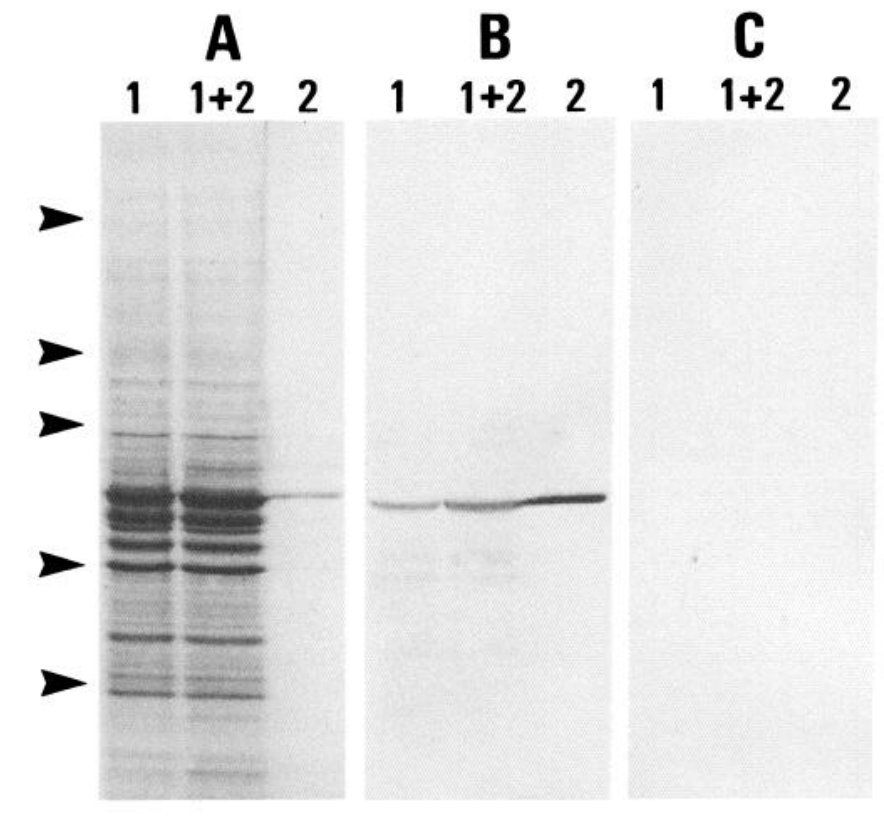

Figure 4. SDS-PAGE gradient gel stained with Coomassie blue (panel A) and posttransfer immunoblots stained with SBV-21 (panel B) and nonimmune mouse serum (panel $C$ ). In each panel, lane 1 was loaded with about $16 \mu \mathrm{g}$ of a crude homogenate of adult rat olfactory nerve layer, lane 2 was loaded with about $6 \mu \mathrm{g}$ of a cytoskeletal preparation from newborn rat forebrain that excluded the olfactory bulbs, and lane $1+2$ was loaded with a mixture of the olfactory nerve layer homogenate and the newborn forebrain cytoskeletal preparation in amounts equal to the individual lanes. In panel B note the single band of vimentinlike immunoreactive material $\left(M_{r}=55 \mathrm{kDa}\right)$ in the three lanes, which corresponds to the dominant band at that position in each lane of the Coomassie-stained gel. Arrowheads designate molecular weight standards run in adjacent lanes; from top to bottom they are myosin (200 $\mathrm{kDa})$, phosphorylase b (94 kDa), bovine serum albumin $(67 \mathrm{kDa})$, ovalbumin $(43 \mathrm{kDa})$, and carbonic anhydrase $(30 \mathrm{kDa})$.

\section{Biochemical characterization of vimentin-like immunoreactive material}

The immunoreactive material from the adult olfactory nerve layer was characterized biochemically and compared with a preparation of cytoskeletal material from the neonatal rat brain which is enriched in vimentin (Dahl et al., 1981). Crude homogenates of the adult olfactory nerve layer contain proteins with a wide array of mobilities as visualized by Coomassie blue staining of SDS-PAGE gels. Nitrocellulose blots of these gels demonstrate that SBV-21 stains only a single band with $M_{r}$ of $55 \mathrm{kDa}$ (Fig. 4). Similarly, in preparations of cytoskeletal material from neonatal rat forebrain, SBV-21 stains only a single band on immunoblots that has the same mobility as the dominant band in the Coomassie blue stained parallel lanes. This dominant band from the neonatal cytoskeletal preparation has been reported to comigrate with authentic vimentin purified from chondrocytes (Dahl et al., 1981), and this, in combination with the immunohistochemical demonstration of abundant staining of immature CNS with anti-vimentin antiserum, has led to its identification as vimentin. Mixing experiments with subsequent immunoblotting demonstrate that the vimentin from the neonatal cytoskeletal preparation comigrates with the immunoreactive material from the adult olfactory nerve (Fig. 4). These results argue that the immunoreactive material from the adult olfactory nerve is either vimentin or an immunologically related protein that has the same apparent mobility on SDSPAGE.

SBV-21 did not stain either neurofilament proteins or GFAP, which were identified by incubation of immunoblots with the 

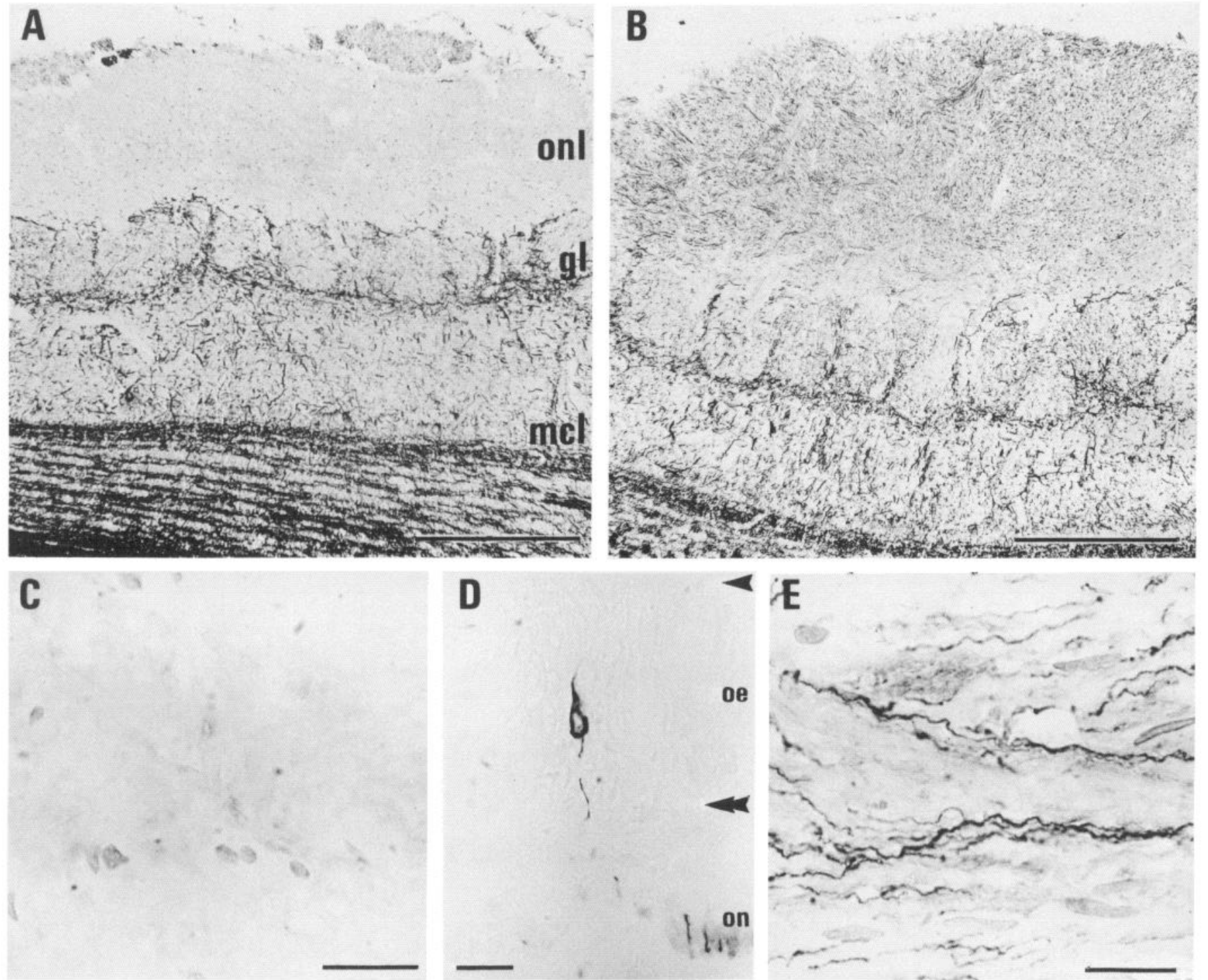

Figure 5. $A$ and $B$, Photomicrographs of the medial and lateral sides, respectively, of a cryostat section of the olfactory bulb stained with anti$\mathrm{M} / \mathrm{H}$ neurofilament antiserum. In both $A$ and $B$ the staining in the deeper layers of the olfactory bulb and the periglomerular layer is equivalent. However, staining in the olfactory nerve layer is apparent only on the lateral side. $C$ and $E$, Higher power of the olfactory nerve layer from $A$ and $B$, respectively. On the medial side $(C)$, there are no neurofilament labeled profiles, while on the lateral side $(E)$, scattered axonlike fibers are stained. $D$, Photomicrograph of a portion of the lateral part of the olfactory epithelial sheet stained with anti-M/H neurofilament antiserum. A single olfactory neuron including its axon descending to the basal lamina (double arrowhead) is stained. In the submucosa, there are several other stained axons in a fascicle of the olfactory nerve (on). The apical epithelial surface is indicated by the single arrowhead. Scale bars, $100 \mu \mathrm{m}$ for $A$ and $B$; $5 \mu \mathrm{m}$ for $C-E$.

corresponding antisera. These experiments also served to confirm the specificity of the other antisera. The anti-M/H neurofilament antiserum stained bands of 200 and $148 \mathrm{kDa}$, while the anti-M antisera stained the $148 \mathrm{kDa}$ band and the anti-L antiserum stained a band of $68 \mathrm{kDa}$ (data not shown). Anti-GFAP immunoreactive material was confined to a single band of 49 $\mathrm{kDa}$.

\section{Localization of neurofilament proteins}

The localization of vimentin-like immunoreactivity to olfactory axons prompted us to study the distribution of neurofilament proteins in the primary olfactory projection (Fig. 5). Each of the three anti-neurofilament antisera, anti-M/H, anti-M, and anti$\mathrm{L}$, gave a similar pattern of labeling. In contrast to the essentially universal staining of the epithelial sheet with the anti-vimentin antibodies, the anti-neurofilament antisera stain only rare and scattered olfactory receptor neurons, and these are found only in the posterolateral part of the epithelium (Fig. 5D). They may be identified as receptor neurons by their location in the middle layer of the epithelium, their bipolar form, and their slender axon, which extends through the basal lamina. The number of these receptor neurons that stain with anti-neurofilament antisera is estimated at less than $0.1 \%$ of the total. Scattered stained fibers are also present in the fascicles of the olfactory nerve, which convey the axonal projection from this part of the olfactory mucosa, but no staining is seen in those fascicles from the medial part. In correspondence with the projection of the epithelium onto the bulb (Clark, 1957; Costanzo and O'Connell, 1978; Land, 1973; Land and Shepherd, 1974), these anti-neurofilament stained axons are seen only in the ventral and lateral portions of the olfactory nerve layer of the bulb, where they are scattered and few in number (Fig. 5, $B, E$ ). There are no labeled 
fibers in the dorsal and medial parts of the olfactory nerve layer (Fig. 5, $A, C$ ). In the remainder of the bulb, these antisera stained the centrifugal and mitral cell axons in the internal granular cell layer and a delicate fiber plexus in the external plexiform and periglomerular layers.

\section{Localization of GFAP and desmin}

In order to further eliminate the possibility that the anti-vimentin staining in the primary olfactory projection is due to cross-reactivity with other closely related intermediate filaments, the patterns of staining with the anti-GFAP and the antidesmin antisera were also assessed and found to be distinctly different from that described for vimentin-like immunoreactivity. Our results with the anti-GFAP antiserum are similar to those reported by Barber and Lindsay (1982). There is no GFAPlike immunoreactivity in the epithelium, but some stained profiles are present in the fascicles of the olfactory nerve in the submucosa. In the olfactory nerve layer of the bulb, GFAP-like immunoreactivity is localized to what appear to be the interstices between bundles of axons (Fig. 6). This corresponds with the localization of filament-containing glia by conventional electron microscopy (Doucette, 1984) and with the localization of GFAP to glia of the olfactory nerve by electron-microscopic immunohistochemistry (Barber and Lindsay, 1982). In addition, anti-GFAP-labeled glial cells were prominent in the glomerular layer and scattered throughout the deeper layers of the bulb.

Staining with the anti-desmin antiserum is largely confined to astroglial-like cells (Dahl and Bignami, 1982), which in the olfactory bulb are located in the deeper layers, and only a few profiles are stained in the olfactory nerve layer. Since rat peripheral tissues known to contain desmin-including the smooth muscle of the uterus, small intestine, and stomach-stain with this antiserum (data not illustrated), it is likely that the antiserum reacts with rat desmin as well as bovine desmin (M. Price, manuscript in preparation). These results suggest that desmin is not present in any substantial amounts in the olfactory nerve layer.

\section{Discussion}

The principal result to emerge from this study is that olfactory sensory neurons in the adult rat contain vimentin or a vimentinlike protein. Furthermore, only a small subpopulation of sensory neurons (less than $0.1 \%$ ) contain neurofilament proteins. This is the reverse of the situation in the vast majority of adult neurons elsewhere in the nervous system that contain neurofilament proteins but not vimentin (Liem et al., 1981; Shaw et al., 1981).

Since some glial cells are known to contain vimentin, we seriously considered the possibility that the staining in the primary olfactory projection was due to supporting cells rather than the olfactory receptor neurons themselves. We were able to rule out this alternative for the following reasons. First, the anti-vimentin stained elements, particularly the cell bodies in the olfactory epithelium and the arborizations in the glomeruli of the olfactory bulb, look very much like the olfactory receptor neurons and their axons as described in Golgi and electronmicroscopic studies. Moreover, an antiserum to GFAP that does label supporting cells in the olfactory nerve and glomeruli (Barber and Lindsay, 1982) produces an entirely different pattern of staining than the anti-vimentin antibodies. Finally and most conclusively, vimentin-like immunoreactivity was localized to olfactory axons in the olfactory nerve layer of the bulb by electron-microscopic immunohistochemistry. Two ancillary points need to be made about the electron-microscopic immunohistochemical findings. First, we are as yet unable to decide whether the lack of staining in some axons in the illustrated micrographs is solely due to incomplete penetration of the antibodies or

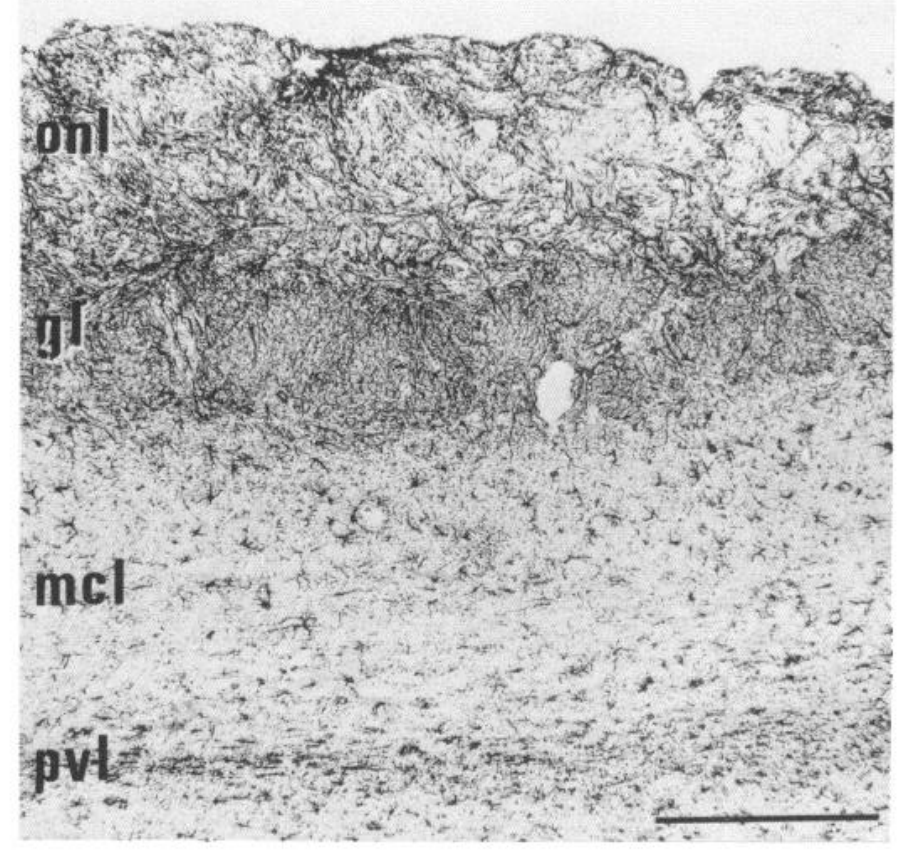

Figure 6. Photomicrograph of a section of the olfactory bulb stained with anti-GFAP antiserum. The labeled processes in the olfactory nerve layer are largely situated between bundles of olfactory axons. Stained glial cells are prominent in the glomerular layer and scattered throughout the remainder of the bulb, including the white matter of the periventricular layer. Scale bar, $100 \mu \mathrm{m}$.

whether there is also true heterogeneity of vimentin expression among the olfactory receptor neurons. Significantly, in electron micrographs of cross sections of the olfactory nerve, not all axons contain intermediate filaments (Andres, 1965). If the immunoreactivity to SBV-21 were limited to these filaments, heterogeneity in axonal labeling could result. Second, glial cells in the olfactory nerve layer are stained with the monoclonal antivimentin antibody SBV-21, indicating that the olfactory axons are not the exclusive location of vimentin, although the axons are by far the most prominent labeled element.

Several lines of evidence argue that the material stained in the olfactory projection is vimentin or a very similar protein. Two monoclonal anti-vimentin antibodies and a polyclonal antivimentin antiserum, which were raised independently against electrophoretically purified vimentin from three different species, produce essentially the same staining pattern. It is extremely unlikely that all three of the above reagents recognize a common cross-reacting molecular species that has the same anatomical distribution as vimentin yet is not vimentin. In the case of SBV21 , the immunoreactive material in the olfactory nerve layer was characterized with SDS-PAGE and immunoblotting. This analysis shows that only a single immunoreactive band is present in olfactory nerve homogenates and that its apparent mobility, $M_{r}=55 \mathrm{kDa}$, is similar to that of vimentin. This immunoreactive band comigrates with vimentin prepared from neonatal rat brain, which is a rich source of the protein (Dahl et al., 1981). While immunolocalization of intermediate filament subunit proteins presents the special problem that many of these proteins share common antigenic domains, we have shown that antisera to neurofilament proteins, GFAP, and desmin produce an entirely different staining pattern than the antivimentin antibodies. This effectively rules out the possibility that the stained material in the olfactory receptor neurons is any of these proteins. However, our results do not establish a complete identity between the immunoreactive protein in the pri- 
mary olfactory projection and mesenchymal vimentin. Although vimentin is coded for by a single gene in hamsters (Quax et al., 1983), it is still possible that posttranslational modifications differ in the two types of tissues. Similarly, we cannot completely eliminate the possibility that the protein in the olfactory axons is the product of a closely related gene.

During the development of the nervous system, vimentin is found in virtually all cells of the proliferating neuroepithelium and migrating neural crest (Houle and Federoff, 1984; Tapscott et al., 1981a, b; Ziller et al., 1983). Coexpression of vimentin and neurofilament proteins has been demonstrated in vivo and in vitro for young postmitotic neurons in the neural tube and the dorsal root ganglia (Bignami et al., 1982; Tapscott et al., 1981 b; Ziller et al., 1983), but by the time adulthood has been reached, vimentin is undetectable in all neurons with the interesting exception of the horizontal cells of the mouse and rat retina (Dräger, 1983; Shaw and Weber, 1983). Instead, the intermediate filament subunit proteins found in mature neurons are typically neurofilament proteins (Liem et al., 1981; Shaw et al., 1981). Our results show that most olfactory receptor neurons do not make the switch from vimentin expression to neurofilament protein expression and thus retain a biochemical marker typical of a juvenile stage in neuronal differentiation. In a minor subpopulation of olfactory receptor neurons (estimated at $0.1 \%$ or less of the total number), neurofilament proteins are detectable; we do not know whether they also contain vimentin. Parallel results have been found with Thy-1 expression. In this case, most of the olfactory receptor neurons and their axons in adult rats lack Thy-1 immunoreactivity (Morris and Barber, 1983; J. E. Schwob, unpublished observations). This cell surface antigen is characteristic of neurons elsewhere in the mature PNS and CNS (Barclay and Hyden, 1978; Morris et al., 1983). Levels of Thy- 1 are very low at birth, and the antigen subsequently accumulates during the first few postnatal weeks to the high levels characteristic of the adult (Barclay, 1979; Douglas, 1972; Mirsky and Thompson, 1975; Zwerner et al., 1977). As in the case of neurofilament proteins, a small percentage of olfactory neurons do express Thy-1 (J. E. Schwob, unpublished observations). Hence, Thy-1 would appear to be a generally expressed biochemical marker of the later stages of neuronal development and of the mature state (Barclay, 1979), which is largely lacking from the olfactory receptor neurons.

Besides the retention of vimentin and the absence of Thy-1 immunoreactivity, olfactory receptor neurons are unique in the mammalian nervous system in several other respects. Embryologically, they are derived from the olfactory placode (Cuschieri and Bannister, 1975), rather than the neural tube or neural crest. Morphologically, they are extremely simple and receive no afferent innervation. They are directly exposed to the external environment. Moreover, during the normal course of adult life or following injury, the population of receptor neurons undergoes attrition by neuronal cell death and replacement from a pool of constantly proliferating stem cells. The newly generated neurons must then grow an axon to reinnervate the olfactory bulb and re-establish olfaction (Graziadei and Monti Graziadei, 1979, 1980; Harding and Wright, 1979; Monti Graziadci and Graziadei, 1979; Moulton, 1974; Oley et al., 1975). These factors might exert a regulatory influence on the olfactory receptor neurons that causes most of them to be arrested at a juvenile state of biochemical differentiation. Further experimental analysis of vimentin expression in the olfactory receptor neurons may help place these neurons within the general framework of the biochemical maturation of neurons as described by Willard et al. (1985).

\section{References}

Andres, K. H. (1965) Der feinbau des bulbus olfactorius der ratte unter besonderer berucksichtigung der synaptischen verbindungen. $Z$. Zellforsch. 65: 530-561.
Barber, P. C., and R. M. Lindsay (1982) Schwann cells of the olfactory nerves contain glial fibrillary acidic protein and resemble astrocytes. Neuroscience 7: 3077-3090.

Barclay, A. N. (1979) Localization of the Thy-1 antigen in the cerebellar cortex of rat brain by immunofluorescence during postnatal development. J. Neurochem. 32: 1249-1257.

Barclay, A. N., and H. Hyden (1978) Localization of the Thy-1 antigen in the rat brain and spinal cord by immunofluorescence. J. Neurochem. 31: 1375-1391.

Bennett, G.S., and C. DiLullo (1985A) Expression of a neurofilament protein by the precursors of a subpopulation of ventral spinal cord neurons. Dev. Biol. 107: 94-106.

Bennett, G. S., and C. DiLullo (1985b) Transient expression of a neurofilament protein by replicating neuroepithelial cells of the embryonic chick brain. Dev. Biol. 107: 107-127.

Bennett, G. S., S. J. Tapscott, and H. Holtzer (1982) Switches in intermediate filament subunit types during neurogenesis. In Changing Concepts of the Nervous System, A. R. Morrison and P. L. Strick, eds., pp. 131-149, Academic, New York.

Berod, A., B. K. Hartman, and J. F. Pujol (1981) Importance of fixation in immunohistochemistry: Use of formaldehyde solutions at variable $\mathrm{pH}$ for the localization of tyrosine hydroxylase. J. Histochem. Cytochem. 29: 844-850.

Bignami, A., L. F. Eng, D. Dahl, and C. T. Uyeda (1972) Localization of the glial fibrillary acidic protein in astrocytes by immunofluorescence. Brain Res. 43: 429-435.

Bignami, A., T. Raju, and D. Dahl (1982) Localization of vimentin, the nonspecific intermediate filament protein, in embryonal glia and in early differentiating neurons. Dev. Biol. 91: 286-295.

Blose, S. H., D. I. Meltzer, and J. R. Feramisco (1984) 10-nm filaments are induced to collapse in living cells microinjected with monoclonal and polyclonal antibodies against tubulin. J. Cell Biol. 98: 847-858.

Bramhall, S., N. Noack, M. Wu, and J. R. Loewenberg (1969) A simple colorimetric method for the determination of protein. Anal. Biochem. 31: 146-148.

Cajal, S. Ramon y (1911) Histologie du Système Nerveux, CSIC, Madrid.

Clark, W. E. LeGros (1957) Inquiries into the anatomical basis of olfactory discrimination. Proc. R. Soc. Lond. [Biol.] 146: 299-319.

Cochard, P., and D. Paulin (1984) Initial expression of neurofilaments and vimentin in the central and peripheral nervous system of the mouse embryo in vivo. J. Neurosci. 4: 2080-2094.

Costanzo, R. M., and R. J. O'Connell (1978) Spatially organized projections of hamster olfactory nerves. Brain Res. 139: 327-332.

Cuschieri, A., and L. H. Bannister (1975) The development of the olfactory mucosa in the mouse: Light microscopy. J. Anat. 119: 277286.

Dahl, D., and A. Bignami (1982) Immunohistochemical localization of desmin, the muscle-type $100 \AA$ filament protein, in rat astrocytes and Muller glia. J. Histochem. Cytochem. 30: 207-213.

Dahl, D., D. C. Rueger, A. Bignami, K. Weber, and M. Osborn (1981) Vimentin, the 57000 molecular weight protein of fibroblast filaments, is the major cytoskeletal component in immature glia. Eur. J. Cell Biol. 24: 191-196.

Doucette, J. R. (1984) The glial cells in the nerve fiber layer of the rat olfactory bulb. Anat. Rec. 210: 385-391.

Douglas, T. C. (1972) Occurrence of theta-like antigen in rats. J. Exp. Med. 136: 1054-1062.

Dräger, U. C. (1983) Coexistence of neurofilaments and vimentin in a neurone of adult mouse retina. Nature 303: 169-172.

Eldred, W. D., C. Zucker, H. J. Karten, and S. Yazulla (1983) Comparison of fixation and penetration enhancement techniques for use in ultrastructural immunocytochemistry. J. Histochem. Cytochem. 31: 285-292.

Graziadei, P. P. C., and G. A. Monti Graziadei (1979) Neurogenesis and neuron regeneration in the olfactory system of mammals. I. Morphological aspects of differentiation and structural organization of the olfactory sensory neurons. J. Neurocytol. $8: 1-18$.

Graziadei, P. P. C., and G. A. Monti Graziadei (1980) Neurogenesis and neuron regeneration in the olfactory system of mammals. III. Deafferentation and reinnervation of the olfactory bulb following section of the fila olfactoria in rat. J. Neurocytol. 9: 145-162.

Harding, J. W., and J. W. Wright (1979) Reversible effects of olfactory nerve section on behavior and biochemistry in mice. Brain Res. Bull. 4: $17-22$.

Hirokawa, N., M. A. Glicksman, and M. B. Willard (1984) Organi- 
zation of mammalian neurofilament polypeptides within the neuronal cytoskelton. J. Cell Biol. 98: 1523-1536.

Houle, J., and S. Fedoroff (1983) Temporal relationship between the appearance of vimentin and neural tube development. Dev. Brain Res. 9: 189-195.

Hynes, R. O., and A. T. Destree (1978) $10 \mathrm{~nm}$ filaments in normal and transformed cells. Cell 13: 151-163.

Jacobs, M., Q. L. Choo, and C. Thomas (1982) Vimentin and 70K neurofilament protein co-exist in embryonic neurones from spinal ganglia. J. Neurochem. 38: 969-977.

Laemmli, U. K. (1970) Cleavage of structural proteins during the assembly of the head of bacteriophage T4. Nature 227: 680-685.

Land, L. J. (1973) Localized projection of olfactory nerves to rabbit olfactory bulb. Brain Res. 63: 153-166.

Land, L. J., and G. M. Shepherd (1974) Autoradiographic analysis of olfactory receptor projections in the rabbit. Brain Res. 70: 506-510.

Lazarides, E. (1980) Intermediate filaments as mechanical integrators of cellular space. Nature 283: 249-256.

Lehtonen, E., V.-P. Lehto, R. Passivuo, and I. Virtanen (1983) Parietal and visceral endoderm differ in their expression of intermediate filaments. EMBO J. 2: 1023-1028.

Liem, R. K. H., C. H. Keith, J. F. Leterrier, E. Trenkner, and M. L. Shelanski (1981) Chemistry and biology of neuronal and glial intermediate filaments. Cold Spring Harbor Symp. Quant. Biol. 46: 341-350.

McLean, I. W., and P. K. Nakane (1974) Periodate-lysine-paraformaldehyde fixative. A new fixative for immunoelectron microscopy. J. Histochem. Cytochem. 22: 1077-1083.

Mirsky, R., and E. J. Thompson (1975) Thy-1 (theta) antigen on the surface of morphologically distinct brain cell types. Cell 4: 95-101.

Monath, T. P., C. B. Cropp, and A. K. Harrison (1983) Mode of entry of a neurotropic arbovirus into the central nervous system. Reinvestigation of an old controversy. Lab. Invest. 48: 399-410.

Monti Graziadei, G. A., and P. P. C. Graziadei (1979) Neurogenesis and neuron regeneration in the olfactory system of mammals. II. Degeneration and reconstitution of the olfactory sensory neurons after axotomy. J. Neurocytol. 8: 197-213.

Monti Graziadei, G. A., F. L. Margolis, J. W. Harding, and P. P. C. Graziadei (1977) Immunocytochemistry of the olfactory marker protein. J. Histochem. Cytochem. 25: 1311-1316.

Morris, R. J., and P. C. Barber (1983) Fixation of Thy-1 in nervous tissue for immunohistochemistry: A quantitative assessment of the effect of different fixation conditions upon retention of antigenicity and the cross-linking of Thy-1. J. Histochem. Cytochem. 31: 263274.

Morris, R. J., P. C. Barber, J. Beech, and G. Raisman (1983) The distribution of Thy-1 antigen in the P.N.S. of the adult rat. J. Neurocytol. 12: 1017-1039.

Moulton, D. J. (1974) Cell renewal in the olfactory epithelium of the mouse. Ann. NY Acad. Sci. 237: 52-61.

Oley, N., R. S. Dellan, D. Tucker, J. C. Smith, and P. P. C. Graziadei (1975) Recovery of function and structure following transection of the primary olfactory nerves in pigeon. J. Comp. Physiol. Psychol. 88: 477-495.

Osborn, M., E. Debus, and K. Weber (1984) Monoclonal antibodies specific for vimentin. Eur. J. Cell Biol. 34: 137-143.

Osborn, M., N. Geisler, G. Shaw, G. Sharp, and K. Weber (1981) Intermediate filaments. Cold Spring Harbor Symp. Quant. Biol. 46: 413-429.

Pinching, A. J., and T. P. S. Powell (1971) The neuropil of the glomeruli of the olfactory bulb. J. Cell Sci. 9: 347-377.

Quax, W., W. Vree Egberts, W. Hendriks, Y. Quax-Jeuken, and H. Bloemendal (1983) The structure of the vimentin gene. Cell 35: 215-223.

Schnitzer, J., W. W. Franke, and M. Schachner (1981) Immunocytochemical demonstration of vimentin in astrocytes and ependymal cells of developing and adult mouse nervous system. J. Cell Biol. 90: 435-447.

Shaw, G., and K. Weber (1983) The structure and development of the rat retina: An immunofluorescence microscopical study using antibodies specific for intermediate filament proteins. Eur. J. Cell. Biol. 30: 219-232.

Shaw, G., M. Osborn, and K. Weber (1981) An immunofluorescence microscopical study of the neurofilament triplet proteins, vimentin and glial fibrillary acidic protein within the adult rat brain. Eur. J. Cell Biol. 26: 68-82.

Tapscott, S. J., G. S. Bennett, and H. Holtzer (1981a) Neuronal precursor cells in the chick neural tube express neurofilament proteins. Nature 292: 836-838.

Tapscott, S. J., G. S. Bennett, Y. Toyama, F. Kleinbart, and H. Holtzer (1981b) Intermediate filament proteins in the developing chick spinal cord. Dev. Biol. 86: 40-54.

Towbin, H., T. Staehelin, and J. Gordon (1979) Electrophoretic transfer of proteins from polyacrylamide gels to nitrocellulose sheets: Procedure and some applications. Proc. Natl. Acad. Sci. USA 76: 43504354.

Valverde, F. (1965) Studies on the Pyriform Lobe, Harvard U.P., Cambridge, MA

Willard, M. B., K. Meiri, and M. Glicksman (1985) Changes of state during neuronal development: Regulation of axon elongation. In $\mathrm{Mo}$ lecular Bases of Neural Development, G. W. Edelman, W. E. Gall, and W. M. Cowan, eds., Wiley, New York.

Willard, M., and C. Simon (1981) Antibody decoration of neurofilaments. J. Cell Biol. 89: 198-205.

Yen, S.-H., and K. L. Fields (1981) Antibodies to neurofilament, glial filament and fibroblast intermediate filament proteins bind to different cell types of the nervous system. J. Cell Biol. 88: 115-126.

Ziller, C., E. Dupin, P. Brazeau, D. Paulin, and N. M. LeDourain (1983) Early segregation of a neuronal precursor line as revealed by culture in a chemically defined medium. Cell 32: 627-638.

Zwerner, R. K., R. T. Acton, and N. W. Seeds (1977) The developmental appearance of Thy- 1 in mouse reaggregating brain cell cultures. Dev. Biol. 60: 331-335. 